\title{
Pemberdayaan Nelayan Dan UMKM melalui Diversifikasi Olahan Ikan Menuju "Desa Iwak" dan Kawasan Minapolitan Di Desa Kalanganyar, Kec Sedati, Kabupaten Sidoarjo, Jawa Timur
}

\author{
Purwadi dan Sigit Dwi Nugrono \\ Universitas Pembangunan Nasional "Veteran" Jawa Timur \\ Jl.Raya Rungkut Madya, Gunung Anyar, Surabaya, Telp. (031) 8706369, Fax (031) 8706372 \\ Email : purwadi@upnjatim.ac.id
}

\begin{abstract}
Abstrak - Desa Kalanganyar adalah sebuah desa di Kabupaten Sidoarjo, Kecamatan Sedati yang luas wilayahnya 2/3 terdiri dari tambak, yang berbatasan dengan desa Buncitan, Sawohan, Cemandi, dan Tambakcemandi. Desa Kalanganyar termasuk wilayah dengan kondisi sosial ekonomi yang perlu ditingkatkan lebih baik lagi. Sumber mata pencaharian masyarakat setempat sangat tergantung dari hasil penangkapan ikan yang sangat dipengaruhi oleh cuaca. Pada saat nelayan tidak bisa melaut dikarenakan cuaca yang ekstrim, maka masyarakat setempat tidak mempunyai sumber penghasilan alternatif. Permasalahan mitra dan potensi untuk mendukung wilayah Kecamatan Sedati sebagai kawasan minapolitan adalah (1) terbatasnya mata pencaharian masyarakat sebagai nelayan, (2) Masih lemahnya ketrampilan Kelompok Budidaya Ikan (Pokdakan) tentang diversifikasi produk berbahan baku ikan., (3) Masih kurangnya pengetahuan dan praktek tentang pengolahan ikan yang bernilai ekonomis.(4) Pengetahuan tentang pengemasan produk berbahan baku ikan masih terbatas (5) Kurangnya pengetahuan tentang pemasaran produk ikan. Metode yang digunakan yaitu Penyuluhan dan Pelatihan antara lain sosialisasi pentingnya diversifikasi produk olahan berbahan baku dari ikan, pelatihan teknologi diversifikasi pengolahan produk dari ikan, pelatihan pengemasan produk olahan dari ikan, pelatihan manajemen pemasaran online dan offline. Hasil yang dicapai dalam pelaksanaan program kegiatan (a). Masyarakat memahami pentingnya diversifikasi produk dari ikan agar ikan mempunyai nilai ekonomis yang tinggi,(b) Pelatihan diversifikasi produk dari ikan berhasil membuat kecap dari ikan dan abon dari ikan bandeng,(c) Berhasil membuat kemasan produk kecap dari ikan dan labeling dendeng dari ikan bandeng, (d). Pemasaran secara online lewat media sosial dan website masih dalam proses desain.
\end{abstract}

Kata Kunci: Minapolitan, olahan ikan, diversifikasi

\begin{abstract}
Kalanganyar Village is a village in Sidoarjo Regency, Sedati District, which covers an area of 2/3 consisting of a pond, which borders the villages of Buncitan, Sawohan, Cemandi, and Tambakcemandi. Kalanganyar Village is one of the areas with socio-economic conditions that need to be improved. The source of the livelihood of the local community is very dependent on the results of fishing which is very influenced by the weather. When fishermen cannot go to sea due to extreme weather, local people do not have alternative sources of income. The problems with partners and the potential to support the Sedati sub-district as a Minapolitan area are (1) limited livelihoods of the community as fishermen, (2) The skills of the Fish Cultivation Group (Pokdakan) are still weak regarding the diversification of products made from fish as raw material, (3) There is still a lack of knowledge and practice regarding fish processing which has economic value. (4) Limited knowledge about the packaging of fish-based products (5) Lack of knowledge about marketing fish products. The method used is counseling and training, among others, the socialization of the importance of diversification of processed products made from fish, training on diversification of fish product processing technology, training on packaging of processed fish products, training on online and offline marketing management. The results achieved in implementing program activities (a). The community understands the importance of product diversification from fish so that fish has a high economic value, (b) Training on product diversification from fish is successful in making soy sauce from fish and shredded fish from milkfish, (c) Success in making soy sauce product packaging from fish and labeling jerky from milkfish, (d). Online marketing through social media and websites is still in the design process.
\end{abstract}

Keywords: Minapolitan, processed fish, diversification 


\section{PENDAHULUAN}

Kabupaten Sidoarjo memiliki potensi sumber daya perikanan dan termasuk dalam 197 kabupaten/ kota dari 33 provinsi yang ditetapkan sebagai kawasan minapolitan. Berdasarkan Kepmen Perikanan dan Kelautan No.32/ 2010 tahun 2012, sedangkan sebagai pusat kawasan kawasan minapolitan adalah Kecamatan Sedati dan Sidoarjo dan kawasan penyanggah minapolitan berada di Kecamatan Waru, Buduran dan Jabon.

Desa Kalanganyar termasuk wilayah Kecamatan Sedati dengan luas 4.476 Ha atau kurang lebih $135.000 \mathrm{~m} 2$. Mata pencaharian masyarakatnya sebagian besar bersumber dari penangkapan ikan yang sangat tergantung dari cuaca. Pada saat nelayan tidak bisa melaut dikarenakan cuaca yang ekstrim, maka masyarakat setempat tidak mempunyai sumber penghasilan alternatif. Kondisi sosial ekonomi masyarakat masuk dalam kategori desa miskin dan tertinggal.

Permasalahan mitra dan potensi untuk mendukung wilayah Kecamatan Sedati sebagai kawasan minapolitan adalah belum ada alternatif sumber mata pencaharian yang mampu menopang kehidupan sehari-hari, ketika nelayan tidak melaut karena cuaca. Hal ini mempengaruhi tingkat kesejahteraan nelayan. Berdasarkan hasil identifikasi permasalahan mitra adalah (1) Masih lemahnya ketrampilan anggota Kelompok Nelayan atau Pokdakan (Kelompok Budidaya Ikan) diversifikasi produk berbahan baku ikan, (2) Keterbatasan pengetahuan dan praktek tentang pengolahan ikan yang bernilai ekonomis, (3) Kurangnya pengetahuan tentang pengemasan dan labeling produk (4) Lemahnya pengetahuan tentang manajemen pemasaran produk ikan, (5) Fungsi kelembagaan belum optimalyaitu koperasi, UKM Pokdakan dan Badan Usaha Milik Desa (Bumdes).

\section{METODE}

Kegiatan ini diawali dengan kunjungan ke lokasi untuk melihat potensi serta permasalahan desa Kalanganyar, yang menghasilkan kesepakatan atas program-program yang akan dilaksanakan bersama yaitu: (a) Penyuluhan tentang pentingnya diversifikasi produk olahan berbahan baku dari ikan bernilai ekonomis, (b) Pelatihan teknologi pengolahan produk berbahan baku dari ikan, (c) Pelatihan pengemasan produk olahan dari ikan $\mathrm{d}$. Pelatihan strategi pemasaran online dan offline, (d) Pemberdayaan kelembagaan koperasi, UKM pokdakan dan Bumdes

Program-program tersebut dilakukan dengan metode penyuluhan dan pelatihan yang meliputi : a) Sosialisasi Diversifikasi Produk Olahan Ikan
Sosialisasi ini untuk mengenalkan produk-produk pengolahan ikan yang bernilai ekonomis, dengan metode tutorial dan contohcontoh pengolahan ikan yang higienis, sebagai kelompok sasaran adalah Bumdes (Badan Usaha Milik Desa) Kalanganyar.

b) Pelatihan Teknologi Pengolahan Ikan

Tujuan kegiatan ini untuk membekali kemampuan masyarakat tentang diversifikasi pengolahan ikan menjadi produk yang bernilai ekonomis tinngi, dengan metode pembuatan olahan berbahan baku dari ikan., sebagai kelompok sasaran adalah Bumdes (Badan Usaha milik desa) Kalanganyar.

c) Penyuluhan teknik pengemasan dan labeling produk

Target kegiatan ini memberi bekal kepada masyarakat khususnya BUMDES ( Badan Usaha Milik Desa) tentang pengemasan labeling produk agar dapat bersaing di pasar.

d) Strategi Pamasaran Produk secara online dan offline.

Maksud dan tujuan kegiatan ini adalah untuk memberi bekal pengetahuan kepada masyarakat tentang manajemen usahakan dan strategi pemasaran secara online dan offline, sebagai kelompok sasaran adalah Bumdes (Badan Usaha milik desa) Kalanganyar.

Pada akhir program akan dilakukan evaluasi dengan cara inventarisasi kendala pada saat melaksanakan program dan mencari solusinya.

\section{HASIL DAN PEMBAHASAN}

\section{Sosialisasi Diversifikasi Produk Olahan Ikan}

Kegiatan ini dilaksanakan pada awal kegiatan sebelum program prioritas dengan tujuan dan manfaat mengenalkan produk-produk pengolahan ikan yang bernilai ekonomis kepada kelompok budidaya ikan (Pokdakan), pentingnya diversifikasi olahan ikan untuk meningkatkan kemampuan dan keterampilan dari kelompok ibuibu dalam teknik diversifikasi produk olahan ikan, dapat dikembangkan menjadi suatu usaha Rumah Tangga, yang dapat mendatangkan nilai tambah keluarga. Selama ini hambatan untuk diversikasi olahan ikan adalah minimnya informasi khusunya melalui kelembagaan yang sudah ada. Sehingga dalam sosialisasi ini disekati pembentukan Badan Usaha Milik Desa (BUMDES). [1] 


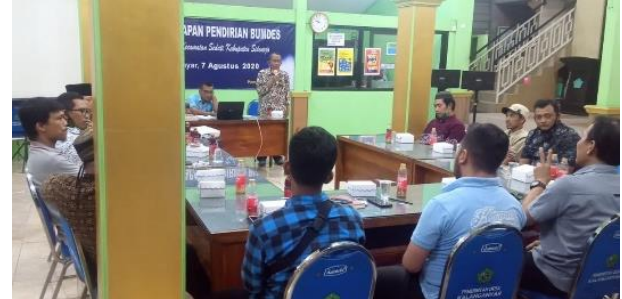

Gambar 1. Sosialisasi Program Pengabdian kepada Masyarakat

\section{Pelatihan Teknologi Pengolahan Ikan}

Tujuan dan manfaat kegiatan ini adalah untuk membekali masyarakat agar mempunyai ketrampilan dalam mengolah berbagai macam olahan dari ikan dan produk olahan ikan akan meningkatkan nilai jual. Produk yang dipilih sesuai dengan kesepakatan dengan kelompok PKK adalah membuat kecap dari ikan bandeng dan dendeng dari ikan bandeng yang merupakan produk samping dari pembuatan kecap ikan bandeng. Hambatan dalam kegiatan ini adalah butuh waktu yang cukup lama, karena ibu-ibu PKK belum pernah membuat produk tersebut [2].

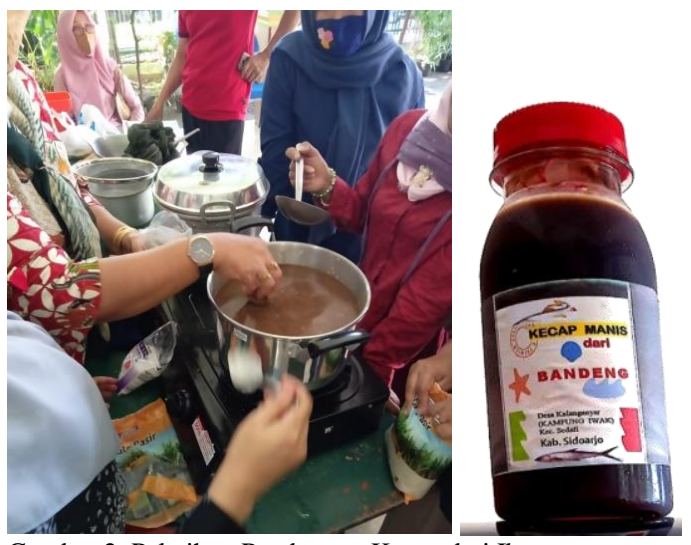

Gambar 2. Pelatihan Pembuatan Kecap dari Ikan

\section{Penyuluhan teknik pengemasan dan labeling produk}

Kegiatan ini bertujuan agar masyarakat memiliki wawasan tentang pentingnya kemasan dan pelabelan suatu produk, sehingga menarik dan dapat bersaing dipasaran. Manfaat dari kebiatan ini adalah agar produk menarik, mudah dipasarkan. Pada kegiatan ini dicontohkan kemasan dan labeling produk dendeng bandeng dan otak-otak bandeng. Hambatan kegiatan ini minimnya pengetahuan dan ketrampilan peserta dalam pembuatan kemasan dan label. Kegiatan ini dihadiri oleh pengurus Bumdes dan ibu-ibu PKK [3].
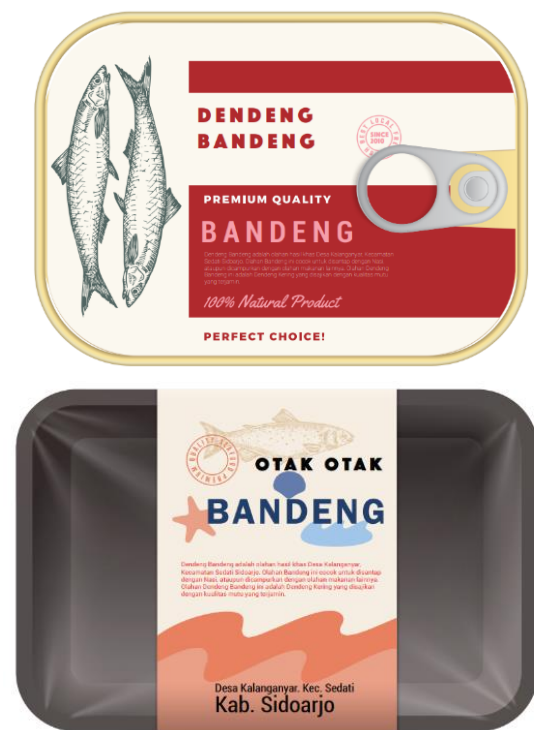

Gambar 3. Beberapa contoh kemasan dari produk ikan (dendeng dan otak-otak bandeng)

\section{Penyuluhan Strategi Pamasaran Produk secara online dan offline.}

Tujuan kegiatan ini untuk memberi bekal pengetahuan kepada masyarakat tentang strategi pemasaran secara online dan offline, yang dihadiri oleh pengurus Bumdes. Sebenarnya sudah ada media sosial untuk pamasaran, tetapi masih terbatas pada kalangan tertentu. Hasil dari kegiatan ini telah disepakati untuk membuat desain website "Kampoeng Iwak" untuk memuat informasi produk-produk ikan. [4]

\section{KESIMPULAN}

Hasil dari pelaksanaan program yang telah dilakukan adalah :

a. Masyarakat memahami pentingnya diversifikasi produk dari ikan agar ikan mempunyai nilai ekonomis yang tinggi.

b. Pelatihan diversifikasi produk dari ikan berhasil membuat kecap dari ikan dan abon dari ikan bandeng.

c. Berhasil membuat kemasan produk kecap dari ikan dan labeling dendeng dari ikan bandeng.

d. Pemasaran lewat media sosial dan website masih dalam proses desain. 


\section{DAFTAR PUSTAKA}

[1] Wonggo, D. dan Reo A.,R., 2018. Diversifikasi Produk Olahan Ikan Di Kelurahan Tongkeina Kecamatan Bunaken Kota Manado. Jurnal Media Teknologi Hasil Perikanan Vol. 6 No. 3.

[2] Handajani, H., Indriastati, S.,A. 2006. Aplikasi Teknik Pembuatan Kecap Ikan Untuk Meningkatkan Pendapatan Ibu Rumah Tangga Di Wilayah Kelurahan Dinoyo. E-jurnal UMM Malang, http://ejournal.umm.ac.id/index.php/dedika si/article/view/894, Vol 3.
[3] Mulyawan,B.I., Handayani,B.R., Dipokusumo, B., Werdiningsih, W.W., Astri Iga Siska, A.I., 2019. Pengaruh Teknik Pengemasan Dan Jenis Kemasan Terhadap Mutu Dan Daya Simpan Ikan Pindang Bumbu Kuning. JPHPI 2019, Volume 22 Nomor 3.

[4] Eviet Sri Setiyorini, E., S., Bambang Pramudya, B., Noorachmat dan Syamsun, M.,. 2018. Strategi Pemasaran Produk Olahan Hasil Perikanan pada UMKM Cindy Group. Jurnal IKM, IPB. Vol. 13 No. 1 ISSN 20858418 http://journal.ipb.ac.id/index.php/ jurnalmpi/ 